\title{
Ageism and Autonomy in Health Care: Explorations through a Relational
}

\section{Lens.}

\section{Introduction}

Ageism, or the 'process of systematic stereotyping of and discrimination against people because they are old' $[9$, p.35], within health and social care has attracted significant attention in recent years. Concerns over its presence have been advanced in both academic and non-academic literature $[6,20,21,22,29,41,46$, 71]. With projections estimating a rapid increase in the number of older people over the coming years; 15.5 million over the age of 65 in the United Kingdom by 2020, and 6 million over the age of 80 by 2030 [18], increasing levels of chronic long term health conditions [23], as well as increasing fiscal constraints on healthcare systems, there are concerns that ageism will intensify [78]. At the same time, the concept of autonomy has developed a prominent role within health care. The notion of autonomy fostered in healthcare law and ethics, however, has been criticised for its overly individualistic conceptualisation in that it pays limited attention to an individual's broader social context and inherent interdependence $[31,57,62]$. Consequently, the range of recognised 'threats' to autonomy, such as lacking capacity ${ }^{1}$ or undue influence ${ }^{2}$ are also interpreted in a narrow, individualistic and binary way. In this paper, I appeal to aspects of relational autonomy ${ }^{3}$ to argue that ageism, understood as a set of negative attitudes about old age or an older person because of their age, may equally operate to threaten an agent's ability to act in a maximally autonomous way when making health related decisions, because of the effect such ageism has on an individual's self-relations such as her feeling of self-worth, self-esteem and self-trust ${ }^{4}$. While there is increasing literature on old age and relational 
autonomy [27, 40, 70, 77], as well as on the advantages of relational autonomy in other contexts $[15,42,43]$, the dynamics of how ageist attitudes interact with relational perspectives on autonomy remains unexplored. It is this lacuna I hope to go some way towards filling in this article. This understanding is of increasing importance not only given the concerns highlighted above about ageism within the care context, but also because of evolving debates around whether there ought to be a specific international human rights convention for the protection of older people ${ }^{5}$. Autonomy plays an important role within human rights principles, and it is therefore essential that we have a model of autonomy that truly reflects the threat posed to decision-making by ageism if specific human rights legislation to protect older people is under consideration. The issue being explored in this paper, then, is an ethical one, but one that exists within a legal framework, and that clearly has legal ramifications.

In order to examine the issue raised here, I will begin by providing a brief overview of the prevailing individualistic account of autonomy in philosophical and ethics literature. Drawing on the critiques of this account, I will assert that this conceptualisation alone cannot account for the ways in which ageism may affect an older agent's ability to act with maximal autonomy, especially when making health-related decisions because of the effect the internalisation of ageist attitudes may have on an agent's self-relations. I will conclude by providing some thoughts on how the argument presented in this paper may perhaps be translated into practice, in light of the critiques of relational autonomy.

\section{Individual v Relational Autonomy}


Two predominant ways of thinking about autonomy have emerged in the literature; the individualistic and the relational ${ }^{6}$. The first focuses largely on an agent's internal functional capacity for decision-making and asserts that the content of the decision made is irrelevant. As long as the agent is able to fulfil the procedural requirements he or she will be considered autonomous. One oftcited definition of such an account is possession of a 'second-order capacity to reflect critically upon one's first order preferences and desires, and the ability either to identify with these or to change them in light of higher order preferences and values' [28, p.108]. An operational example of such an account of autonomy can be found in capacity assessment tests. Under the Mental Capacity Act 2005, for example, an individual must be able to understand and retain information relevant to the decision in question, use the information to help her reach the decision and finally, be able to communicate her decision? The Act also permits unwise decisions to be made if these criteria are fulfilled ${ }^{8}$. This individualistic, act-specific account, frequently enunciated through (and confused with) capacity assessments, dichotomizes autonomy in that it asks whether an agent is able to satisfy certain procedural or functional requirements. If yes, then the agent is autonomous (has capacity); if not, then she is deemed non-autonomous (not to have capacity). As Donnelly argues, capacity in the legal sense has become seen as the 'gatekeeper' to autonomy [26, at p.90]. If a patient is deemed to have capacity (of which there is a presumption under the Mental Capacity Act $^{9}$ ) then that person is deemed autonomous, or more specifically, the decision they are purporting to make is assumed to be autonomous. There is little subsequent (or even prior) examination of the nature of the assumed autonomy. In light of this, both autonomy and capacity are considered binary constructs - either we are capacitous (and therefore 
autonomous) or we are not. This point will be considered further in section IV. Most procedural accounts of autonomy therefore require 'critical reflection, authenticity, and content neutrality' [12, p.411]; they ask whether the person possesses the necessary cognitive functions and if so, the decision made is to be considered an autonomous one even if it is also considered to be 'unwise'. As several critics have argued, however, behind this account of autonomy lies a mythical liberal (male ${ }^{10}$ ) agent; the self-sufficient, self-determining individual who encounters no physical or psychological encroachment on his person from others, and for whom dependency is undesirable ${ }^{11}$; an individual who is able to extract her or his thought process from the influences of others. Despite these strong criticisms, autonomy retains its position as an important principle in both law and ethics because it upholds certain ideas that are deemed valuable [34]. It epitomises the notion that we may live a life that is true to ourselves, true to our own authentic choices, and avows an inherent respect for our subjective experiences, our embodiment and our individuality ${ }^{12}$. Indeed, for older people, empirical research $[3,7,51]$ suggests that autonomy (in some format) is a particularly important concept; it denotes retention of independence at a time when there may be increasing frailty, dependency, engagement with health and social care services, and negative stereotyping of their capabilities. The criticisms directed towards autonomy outlined above are of its interpretation as individualistic; the suggestion that we make decisions in a perfunctorily procedural manner, not necessarily in the values autonomy upholds per $\mathrm{se}^{13}$ or in the value autonomy has for older people. As we shall see, however, an individualistic conceptualisation of autonomy does not adequately reflect the everyday lived experiences (both positive and negative) of older people. 
In contrast to the individualistic construction, the concept of relational autonomy attempts to incorporate our experience of embeddedness in relations, both the inherent, underlying reality of such embeddedness, and the oppressiveness of its current social forms' (emphasis added) [62, p.10]. On the one hand, it is causally relational because it is affected by relationships with others on both a macro and a micro level; it does not exist or operate in a vacuum subject only to the will and constraints present within an individual as the procedural account would imply. Even the individualistic conception of autonomy recognises that autonomy may certainly be compromised where there are individually coercive relationships operating in relation to specific decision-making. One example of this is $\operatorname{Re} T$ [75], a case concerning the validity of the refusal of a blood transfusion by a young, pregnant Jehovah's Witness. Lord Donaldson held that in instances where undue influence may be present, the real question is 'does the patient really mean what he says or is he merely saying it...because the advice and persuasion to which he has been subjected is such that he can no longer think and decide for himself?' [75, at 113]. Lord Donaldson's use of the term 'no longer think and decide for himself' in particular is a resounding reinforcement of the impact that undue influence may have on a liberal account of autonomy as non-interference. Relationality, however is more expansive in that it is able to situate an individual within her broader social context and recognise that autonomy may also be threatened where there is stigma attached to being a member of a societal group, and that this may in turn impact on the way an individual makes certain decisions because of the disproportionate impact such stigmas have on a person's self-relations ${ }^{14}$. As Oshana [67] notes, this is not to suggest that individualistic accounts have no relational elements, but it suggests that the way we view such factors should be extended from simply looking at 
how actions threaten autonomy (such undue influence outlined in $R e T$, above), to considering how broader and subtler oppressive forces such as attitudes and beliefs about individuals and groups because of their membership to that group may also threaten maximal autonomy and the authenticity of a decision ${ }^{15}$. In this sense, relational autonomy is concerned with how autonomy interacts with an individual's relationships on all levels; micro, macro and indeed her relationship with herself. A relational conceptualisation goes further, however, and recognises that relationships may also strengthen an individual's ability to act with maximal autonomy. It may be seen as constitutively relational in the sense that interdependence and positive relationships with others are an essential element to autonomy in the first place. In other words, individuals are simply not able to act in a maximally autonomous way without relationships or a social context within which to operate ${ }^{16}$. Indeed, and as Oshana argues, 'the objective social criteria according to which we judge someone as autonomous...are independent of the individual's internal state' $[67$, p.85]; in order to be considered autonomous, we must be considered by others to have the requisite properties to act autonomously. In light of this, then, maximal autonomy requires positive relationships of recognition on both a micro (individual) and macro (societal) level. Drawing on a relational account of autonomy allows us to retain the value implicit in the concept but also recognise that autonomy is a far more flexible concept than it has traditionally been understood.

In addition, a more expansive relational conceptualisation, and in particular one that is concerned with an individual's relationships on all levels, including selfrelations, both presupposes and reinforces the idea that the ability to act autonomously is not black and white; it is more intuitively understood as 
existing on a spectrum from minimal to maximal. This more accurately reflects the idea that oppressive attitudes and socialization such as ageism have differing degrees of impact on different individuals, and therefore on their ability to act autonomously, as well as better reflecting the idea that self-relations are not a simple binary idea either. As an individual, I do not look at myself in either a 'positive' or a 'negative' light. I may look at different aspects of my being, my personality or appearance with different degrees of positivity or negativity. A relational conceptualisation allows us to focus on the precise ways in which subtle attitudes such as ageism may impact on the way an individual views herself, and therefore her autonomy, rather than simply asking whether a person is able to fulfil certain functional criteria ${ }^{17}$. Finally, relationality does not focus solely on the decision-making process. In the context of old age, and in particularly Fineman's [31] account of relationality which emphasises interdependence, forces us to recognise that while many older people retain the ability to make autonomous decisions on the procedural account, some may find it difficult to execute these choices without dependence on others. For many older people ${ }^{18}$, autonomy could be understood as a two-fold process; decisionmaking, and the execution of their decisions. If simply making decisions is all that is required of the procedural account, without any means of executing them, then the decision and its contents are rendered meaningless; autonomy risks becoming an empty concept, bereft of value for many older people who do depend on others on a daily basis to give effect to their choices ${ }^{19}$.

\section{Ageism in Care and its Impact on Self-Relations}

If 'ageism' refers to a set of attitudes towards an individual (or group of individuals) solely based on age then logically it denotes attitudes towards 
someone of any age, but importantly it must be because of their age. The empirical research suggests that the main features of the prevailing stereotype of the older person, the focus of this paper, are as being less capable and of lower status, $[39,80]$, or as Butler enunciates, 'senile, rigid in thought and manner, oldfashioned in morality and skills...' [19, at p.35]. It is interesting to note for the purposes of this paper, then, that the prevailing ageist and negative stereotype of the older person is as someone who lacks the ability to act autonomously; who is entirely dependent on others. At the core of this representation, as with any stereotype, is a lack of individual recognition, preferring to consider older people, and the older population as a homogenous group, and burdensome [80]. This highlights the first of two key distinctions that emerge from the literature on ageism; the contrast between 'macro' and 'micro' level ageism. These terms denote the levels on which ageism may operate; 'macro' referring to ageism found on a broad organisational or societal level such as in the media or popular culture $^{20}$, whereas 'micro' level ageism denotes ageist attitudes held by individuals. Macro ageism may frequently buttress micro level ageism, but more invidiously, it may be hidden under the guise of other objectives, such as health care rationing policies ${ }^{21}$. Although 'macro' ageism will not be discussed in detail here, it is important to be aware that individual ageism may be frequently reinforced, and caused by, macro level ageism. The second, more critical, distinction that emerges from the literature is between attitudes and behaviours; the difference is 'between ageism, which is a feeling or belief, and age discrimination, which involves behaviour or treatment' [41, p.12]. Clearly these two concepts are not entirely unconnected; age discrimination will, for the most part, naturally happen as a result of ageism. As has been established, the focus in this paper is on the way ageism, that is, the attitudes underpinning actions such 
as age discrimination, impacts on the autonomy of an older person. The way ageist attitudes affect autonomy is a far more interesting concept, and difficult to pinpoint, than the way age discrimination or actions affect autonomy. If a doctor withholds information about a particular treatment from an older patient because of the patient's age, and because he does not think it is a worthwhile treatment for someone 'old', the link between the withholding of information and how the patient's autonomy is compromised is easy to see; the patient does not have access to information that enables the exercise of autonomy ${ }^{22}$. Similarly, if an older person residing in a care home is subjected to physical or verbal abuse by someone who knows that, because of their age, they are unable to defend themselves, and threatened with 'repercussions' if they tell, it is not difficult to see how this may directly threaten their autonomy either. The scope of this paper is to use the concept of relational autonomy as characterised in the preceding section, and which emphasises the place of self-relations within relational autonomy, to illuminate how a decision may appear unproblematic (legally) but the negative attitudes and stereotypes of older people as indicated above, underpinning such structures may threaten the autonomy of the older person because of the effect they have on an individual's self-identification. In order to do this, it will be helpful to consider two brief examples:

Elizabeth, 83, lives in a nursing home. Although she generally does not mind living there, there is one carer who is rough when attending to her, calling her a 'whingeing old bag' and when asked by Elizabeth to be less rough, replied by saying, "Shut up, you have to take this sort of treatment at your age, you're not really a human anymore, you're just an animal"23. Elizabeth does not report the incidents because she believes that the treatment is to be expected now she lives 
in a nursing home. To Elizabeth the conduct is perfectly normal; she is less worthy of respect because she is 'old' and lives in a care home. The attitude that because of her age this sort of behaviour is acceptable has been normalised.

Cassie, 70, is diagnosed with early stage breast cancer. She expresses concern for the total mastectomy that her doctor recommends, and indicates that her preference would be for a lumpectomy instead. Upon hearing her thoughts, her doctor laughs at her and asks 'Why worry about keeping your breasts at your age?' Cassie relents, and believes her doctor will think she is silly for wanting to keep her breasts at her age if she were to pursue her preferred treatment ${ }^{24}$.

In both of these scenarios there is clear wrongdoing. It could be argued that Elizabeth's decision not to denounce what is effectively verbal abuse is not fully autonomous, as she seems to have mistaken beliefs relating to what is to be expected in her circumstances. Cassie's autonomy, too, may be questioned, particularly if the range of options the doctor offers her is limited based on her age. The analysis in this paper, however, seeks to highlight how the attitudes behind either the carer or the doctor's actions, (of the carer or of the doctor) may threaten Elizabeth and Cassie's autonomy. Can the concept of relationality point us in the direction of how to account for the ways in which the attitudes that underpin the wrongdoing in these scenarios may also constitute a threat to Elizabeth and Cassie's autonomy? More specifically, can the concept of selfrelations shed any light on this matter? The perspective derived from relational autonomy is that if self-relations instil a confidence in ourselves to act with authority; they enable us to validly consider ourselves as authors of our own 
lives, and makers of our own decisions, then if we are not able to view ourselves as a '...competent deliberator...it is hard to see how one can take oneself seriously in one's practical reasoning about what to do' $[2$, p.132]. This argument sits ill-at ease with individualistic accounts of autonomy, which simply require a set of functional procedural conditions to be fulfilled before an agent can be considered autonomous. The two ideas (self-relations and procedural or individualistic autonomy), however, are not wholly incompatible or irreconcilable. So, in order to be able to reflect critically on a particular choice or decision, relational autonomists who assert the importance of positive selfrelations might suggest that we must also possess a self-confidence that we have the ability to reach a minimum level of critical reflection in the first place, or therefore that a decision made in light of a lowered sense of self-worth may not be maximally autonomous. If a procedural account of autonomy requires us to rely on our critical reflection and on our capacity for critical reflection, then this dual reliance is only possible if we have self-trust and self-worth [38, pp.103-4]. Simply going through the procedural motions would render autonomy a vacuous concept. Without self-trust or self-worth, we may very well be acting autonomously on the procedural account, but the decisions would not necessarily mean anything to us. Furthermore, if negative self-relations also affect our ability to view ourselves as someone worthy of respect and therefore deny our personal authority with which to act with conviction when making decisions, this is counterintuitive given the very reason we value autonomy in the first place. If, as argued earlier, the value of autonomy is in its ability to enable us to live a life that is authentically ours, then not having trust or confidence in our ability to make decisions that serve that purpose clearly goes against this very value. Negative self-relations seemingly preclude us from being 
able to realise the reason we valorise autonomy in the first place. It is these aspects of self-relations that may be damaged by ageism, through an internalisation of the attitudes, such as weakness, worthlessness or inferiority, which may underpin such actions ${ }^{25}$, as demonstrated in the two examples. The older person, such as Elizabeth or Cassie in the examples above, may no longer have the reflective or evaluative abilities required to act with a maximal degree of autonomy, because she has internalised the ideas and assumptions based on her old age and this in turn precludes her from viewing herself as a competent agent ${ }^{26}$, or someone worthy of being considered a competent or valuable agent in her own right by others. To be clear, the analysis provided here does not necessarily suggest that on every occasion where there are ageist attitudes will there be a threat to maximal autonomy ${ }^{27}$; the important factors here is that there will almost certainly be a threat to maximal autonomy when the ideas espoused by the ageist attitudes have been internalised, or normalised, by the older person and this has, in turn, affected her decisions.

So, to return to the examples provided above, in Elizabeth's scenario the attitudes espoused by the carer have threatened Elizabeth's autonomy because of what it has instilled or reinforced in her; a lowered sense of self-worth in that she now believes she is less deserving of a respectful attitude because of her advanced age and the consequences of her old age (living in a nursing home). She effectively has a lowered sense of self-worth based on her old age. In turn, this has taken away her ability to see herself as a competent, worthwhile agent, and critically reflect over the decision to report or not. Similarly, Cassie now has a lowered sense of self-worth as a result of having internalised the attitudes expressed by her doctor; she views her physicality, and more specifically her 
female embodiment, as less important now because she is older. The internalisation of the ageist attitudes held and espoused by her doctor has influenced her decision into one that she may have otherwise made differently. Objectively, she may display what appears to be rational, un-coerced ${ }^{28}$ selfdetermination, but an appeal to the model of relational autonomy presented in this paper allows us to recognise that her negative self-relations preclude her from making a maximally autonomous decision over her choice of treatment ${ }^{29}$. This is, of course, only one analysis of Cassie's situation. There may, and almost certainly will be, additional factors in her decision-making, part of which is discussed below in a contrasting scenario. However, the possibility that ageism may operate in a way that is perhaps more subtle than in, for example, the first scenario, should alert us to explore more intricately the different facets of what autonomous decision-making in healthcare means for older people, as Donnelly indicates [26].

Consider an alternative example, whereby instead of maintaining silence because she feels she is older and worthless, Elizabeth recognises that the actions of her carer are wrong, and that she doesn't deserve such treatment solely because she lives in a nursing home. However, she chooses not to report the behaviour because overall, she likes the nursing home and doesn't want to be seen as a troublemaker ${ }^{30}$, especially as hearing of this mistreatment would deeply upset her son with whom she has a close relationship. Similarly, let us imagine that Cassie, offended by the doctor's words, nevertheless pursues a lumpectomy, as she does not want to undergo highly invasive treatment, which would mean taking too much time away from caring for her husband who suffers from dementia. On these facts, the choice to keep quiet or over which treatment to 
undergo is not because the ways in which Elizabeth or Cassie self-relate have necessarily changed. There is no indication in this example that the attitudes that underpin either the carer or the doctor's behaviour have impacted on either Elizabeth or Cassie's self-relations or self-identification. This does not, of course, make the actions condonable, nor does it mean that their decisions are maximally autonomous ${ }^{31}$. The difference between the examples, however, is one of subjective recognition. In all instances there is an objective element to the circumstances; some form of wrongdoing has, in fact, occurred, irrespective of whether or not it is recognised as such by Elizabeth or Cassie. The key difference between the scenarios, however, is the presence of subjective recognition by individual; whether the act is subjectively recognised as improper by the person who experiences it. In the most recent example, Elizabeth subjectively recognises the impropriety of the actions but makes a conscious decision not to act on it, albeit in pursuit of the desire for a quiet life and not to upset her son; to force her to report may constitute a greater threat to her autonomy than to respect her choice not to. In the first example, however, no action can be taken (by Elizabeth) because she does not recognise the wrongness of the act, or the ageism that lies behind it.. Focussing on this highlights the fact that the failure to 'see' ageism is central to its internalisation. Indeed, recent studies [10,13] have indicated a significant difference in the rates of mistreatment or neglect reported by staff compared to those reported by care receivers ${ }^{32}$, or have explicitly demonstrated a lack of recognition by older people of conduct that is improper. This discrepancy may suggest that there has been, to some extent, an internalisation of the idea that such conduct is acceptable, or 'normal', for older people, particularly those who encounter such treatment within the health and social care system. More worryingly, this also implies that such conduct may 
consequently be significantly underreported. It is for these reasons that it is necessary, in the next section, to highlight some possible practical dimensions to translating such a theory in to practice.

\section{The Problems of Relational Autonomy: Putting it into Practice}

The argument presented in this paper in terms of conceptualising the link between ageism and autonomy is largely theoretical. Nevertheless, this raises the question of how such an argument can be translated into practice. Can ageism be recognised in law or policy as a threat to autonomy, and if so, how? Clearly this task will not be easy, not least because, as mentioned earlier, the law operates so as to dichotomize autonomy through the legal concept of capacity; either an agent has capacity and is therefore autonomous in the eyes of the law, or not. In this section, however, I hope to highlight some of the practical dimensions of adopting a relational approach, which necessitates more flexibility than simply dealing with these under the rubric of mental capacity law. It is worth noting first that relationality has been criticised primarily on the basis of its potential for increased paternalistic responses $[14,45]$, such as mandatory reporting, or increased surrogate decision-making. John Christman [14], for example, argues forcefully that a relational approach could not only be dangerous, marginalising the voices of those who already oppressed as nonautonomous ${ }^{33}$, but also because of the potential for relational autonomy to allow forcible state intervention when someone does not meet the relational model of autonomy he critiques (which, will inevitably, he argues, always be the case). He summarises by suggesting that '[i]t is one thing to publically criticize modes of social practice that denigrate their participants, but it is another to define autonomy in a way to claim that those participants are not fully functioning 
agents at all' [14 at p.158]. Although Christman's criticisms have intuitive force, there are a number of key points to make here. Firstly, Christman's critique is predominantly directed towards Oshana's account of perfectionist relational autonomy [67], which itself rests on the assumption that autonomy, like capacity, is a binary construct, and a notion that I have explicitly rejected above $^{34}$. The arguments in this paper rest on the construction of autonomy and autonomy capabilities more flexibly; that autonomy exists on a spectrum ${ }^{35}$. The account that places self-identification as a core feature of autonomy, such as presented in this paper, by its very definition cannot rest on an either/or construction of autonomy because the way an individual self-identifies in light of external relationships is not an either/or concept. Not only does Christman's critique predicate itself on the binary construction of autonomy then, but so does the perfectionist account that he critiques. Indeed Christman himself recognises that other relational autonomy theorists promote the existence of autonomy on a spectrum, and he quotes Nedelsky to this effect ${ }^{36}$. Christman's concerns, then, are perhaps best read as a critique of the perfectionist account of relational autonomy rather than a wholesale rejection of all relational accounts. Furthermore, if the predominant concern with relational theories is that responses may be inadequate, insufficient or overly paternalistic, this does not necessarily mean that we should simply adopt the individualistic account of autonomy so as to avoid difficult questions about whether the responses are working or are best suited to a given task. As feminist scholars have argued in relation to law's responses to gender inequality ${ }^{37}$, it may be that the law itself in its current format is insufficiently equipped to deal with more nuanced and relevant theories. Indeed it is submitted here, that such overly paternalistic responses would be a misreading of the argument presented in this paper. 
Adopting such responses where autonomy is compromised by the internalisation of ageist attitudes may only serve to diminish the older person's self-relations even further. Taking decision making out of their hands compounds the idea that she is less capable by removing control over the decision to a third party ${ }^{38}$. Such a response only asks whether the person's autonomy is compromised or not when in fact a legal response should be addressing why autonomy is compromised on those particular set of facts. By exploring the threats to autonomy in more detail, be they ageism-related or not, the courts (if we are to seek a legal response) are better able to respond in a way that emphasises the task of promoting maximal autonomy. As Friedman [35, p.157] argues in relation to domestic violence, the best response may very well be to bolster the agent's self-relations so that not only is she able to recognise instances of such mistreatment, but also, and perhaps more importantly in light of the arguments put forward here, they are able to recognise the negative attitudes that underpin such acts. One method of achieving this sort of outcome in England and Wales, however, may be by utilising the High Court's inherent jurisdiction ${ }^{39}$. The decision of the Court of Appeal in $D L^{40}$ confirmed that the inherent jurisdiction has survived the implementation of the Mental Capacity Act as a 'safety net' 41 to protect those who may not lack capacity under the Mental Capacity Act's provisions, yet nevertheless remain vulnerable because of other factors. Although rightly avoiding the impossible task of providing an exhaustive list of when an adult may be considered 'vulnerable', the court in $D L$ explicitly recognised that instances of 'elder abuse' may meet this criterion and therefore be sufficient to invoke the jurisdiction ${ }^{42}$. A full analysis of the remit of the jurisdiction post-Mental Capacity Act is beyond the scope of this article, and has been discussed elsewhere [47]. However if, in theory at least ${ }^{43}$, its primary 
function remains to '[facilitate] unencumbered decision-making...free of external pressure' [50, para. 62], under the arguments presented here the inherent jurisdiction, buttressed by other policy measures such as state appointed advocates $^{44}$, or a system of supported decision-making as found in other jurisdictions ${ }^{45}$, may be better suited to understanding and encompassing ageism and promoting maximal autonomy for older people. The responses suggested here may, in addition, be better able to promote positive relationships. The Court of Protection in the case of London Borough of Redbridge $v G[52,53]$ has recently highlighted the role of positive relationships within older peoples' lives. The case concerned a 94-year old lady, G, who had been subjected to coercion at the hands of her live-in carer, $\mathrm{C}$, and it fell to the Court of Protection to determine whether G lacked capacity under the Mental Capacity Act, or if not, whether it would be possible to invoke the inherent jurisdiction to protect her from C's influence. There are criticisms to be made of the judgments handed down by Russell J in this case, notably the fact that G was found to have dementia and therefore lacked capacity under the Mental Capacity Act, when in reality the clear cause of her ambivalent decision-making was C's influence. However, one feature of the judgments does bear thinking about further and is a welcome acknowledgment of how positive relationships can build positive self-relations. For nearly 80 years $G$ had been a member of the same church, and at points Russell J even refers to G's relationship with the church and her fellow churchgoers as being her 'church family' [52, para. 84]. It is welcoming to see the emphasis that Russell J places on G's positive relationships with members of her church; it indicates an acknowledgement by the Court of how relationships may operate to promote a person's wellbeing and sense of self. In light of the decision in Aintree ${ }^{46}$, where it was held that decision-makers, in determining what course 
of action would be in a patient's best interests under the Mental Capacity Act, must take into consideration a person's welfare in 'the widest sense, not just medical but social and psychological' [1, para. 39], there is no reason why a similar approach may not be adopted by the courts in relation to other vulnerable adults, such as those whose autonomy may be threatened by the internalisation of ageist attitudes ${ }^{47}$. Notably, Russell J's decision in this particular case demonstrates an acknowledgment of the importance of (re)developing positive relationships to promote a person's wellbeing. Surely a recognition therefore that this in turn enhances their autonomy, and that autonomy is therefore not a binary concept would be the next logical step in this process? Along with accentuating the need to minimise ageism, the arguments presented in this paper also logically indicate that positive social networks should also be emphasised further in any response, whether it is a judicial, social or policy response, to ageism-encumbered decision making. It is welcoming to note that following Aintree and London Borough of Redbridge $v G$, the courts are gradually beginning to understand the importance of such relationships when making decisions, and particularly care-related decisions.

\section{Concluding Remarks}

By using a relational lens, the arguments presented in this paper have sought to illustrate how ageism, understood as a set of attitudes about older people or an individual older person, may be internalised and threaten autonomy. There will, of course, be additional factors involved in any decision-making process for older people. The aim here has not been to disentangle all these factors. It is to specifically draw attention to how ageist attitudes, as just one of these factors, may threaten an older person's autonomy. In order to be cognisant of this what 
we must ask is not 'how can ageist attitudes in health and social care be understood in light of the existing individualistic model of autonomy'? The answer to this is that these accounts of autonomy are not adequately suited to this task. What we should be asking is, 'how can autonomy be (re)-constructed so as to address the effect of ageist attitudes within health and social care?' This, in turn, potentially has broader ramifications; we should not be trying to fit the issues that older people face into existing legal and ethical frameworks, but should be developing new ones to account for and deal with these issues.

\footnotetext{
${ }^{1} \operatorname{Re} C$ [1994] 1 All ER 819 [75] and subsequently ss.2-3 Mental Capacity Act 2005; and for an academic critique of these provisions, see [57].

${ }^{2}$ See Re T (Adult: Refusal of Medical Treatment) [1993] Fam 95 [69, 75].
}

${ }^{3}$ Relational autonomy has been described as an 'umbrella term', focusing on the analysis of 'implications of the intersubjective and social dimensions of selfhood and identity for conceptions of individual autonomy...' [58, p.4].

${ }^{4}$ These characteristics are sometimes considered as part of the broader concept of self-respect: [5].

${ }^{5}$ United Nations Open-Ended Working Group on Ageing, established by General Assembly resolution 65/182, 21 $1^{\text {st }}$ December 2010; 81].

${ }^{6}$ There is considerable variation in the terms used to describe the two visions of autonomy. Alternatives for the individualistic include: procedural, internalist, liberal and content-neutral. Alternatives for the relational include: externalist, socio-relational. This paper is not concerned with the subtle differences between each of these theories, and the terms individualistic or procedural autonomy are used to reflect the former, and relational to reflect the latter.

${ }^{7}$ Mental Capacity Act 2005, s 3(1)(a)-(d)

${ }^{8}$ Mental Capacity Act 2005, 2 1(4). It is also important to note here, however, the difference between capacity and autonomy. Although significantly linked, capacity, a legal concept, is often seen as the 'gatekeeper' [26] to autonomy, which is essentially a philosophical concept; if you have capacity in a legal sense, then you are considered able to act autonomously. 
${ }^{9}$ Mental Capacity Act 2005 s.1(2) 'A person must be assumed to have capacity unless it is established that he lacks it.'

${ }^{10}$ Although this paper is not concerned with the feminist criticisms of the autonomous agent as being 'male' per se, i.e. the distinction between a feminine and masculine construction of autonomy, it is worth noting that a number of feminists have been critical of the atomistic conception of autonomy given its propensity for being orientated towards the masculine conception of the self. Naffine for example, argues that ' $[t]$ he autonomy of the individual...was explicitly reserved for the male' [60, p.105]. Similarly, Gilligan argues that 'the capacity for autonomous thinking, clear decision-making, and responsible actions - are those associated with masculinity and considered undesirable as attributes of the feminine self [37, p.17]. See also: $[17,59]$.

${ }^{11}$ Martha Fineman, one of the leading critics of autonomy on this count, argues that '[the] liberal subject...is indispensable to the prevailing complementary ideologies of personal responsibility and the noninterventionist or restrained state...The image of the human being encapsulated in the liberal subject is reductive and fails to reflect the complicated nature of the human condition' [32, p.17]. See also: $[31,55,63]$.

12 These ideas may seem individualistic in themselves, and therefore paradoxical to the argument that autonomy should be understood relationally, however there is a clear distinction to be made between saying that the values that autonomy upholds are individualistic, and that autonomy itself is individualistic. Simply because the values may be interpreted in an individualistic manner does not necessarily mean that their gatekeeper (autonomy) should also be.

13 There is, of course, a body of literature that argues that autonomy is a 'thoroughly noxious' concept [44], however this seemingly ignores the values autonomy upholds, which is a primary focus of this paper and of relational autonomists in general. The assumption in this paper is that autonomy itself is an important concept because of the values it embodies, but the procedural account is unduly atomistic, and a relational model should be understood as the more appropriate conceptualization.

${ }^{14}$ Decisions made under such conditions may attract what Stoljar terms the feminist intuition, 'which claims that preferences influenced by oppressive norms of femininity cannot be autonomous' [79, p.95]. Oshana explains this by arguing that being autonomous under the 
procedural conceptualisations of autonomy does not lack any socio-relationality, but that the agent's 'psychological condition...is alone important for her autonomy' [67, p.85].

${ }^{15}$ It is worth noting here, however, that Marina Oshana presents a 'perfectionist' account of autonomy, that is, someone who willingly and voluntarily surrenders their autonomy, such as the deferential wife, cannot be considered autonomous in doing so. The argument presented in this paper should be distanced from this perspective for two reasons. Firstly, because this perfectionist relational account fails to realise the idea that autonomy is a more flexible, nonbinary concept (see below, n. 17). Secondly, Oshana's account does not rely on the idea of selfidentification as a central tenet of autonomy, which this article does.

${ }^{16}$ See, for example: $[36,64,83]$.

17 This idea in particular has been used in different contexts by different authors. For example, Schwartz [76] argues that the notion of 'perfect' autonomy does not exist, but rather that we should recognize its existence on a spectrum from minimal to maximal autonomy. Similarly, Donnelly [26, p.41], drawing on the work of Joseph Raz, advances the idea that autonomy is an 'achievement', moving beyond this dichotomization of autonomy found in traditional health care law and ethics. She suggests that our ability to act autonomously is, in fact, continuously evolving towards a state of achievement, rather than being fixed.

${ }^{18}$ This idea is not just applicable to older people, but applies to any one of any age. The idea that autonomy is a two-fold process as presented here is, however, easier to see when illustrated in the context of old age where individuals may exhibit greater situational or pathogenic vulnerabilities, that is, those vulnerabilities that are context specific (situational) or those that are 'generated by...morally dysfunctional or abusive interpersonal and social relationships and socio-political oppression or injustice' (pathogenic) [54, p.9].

${ }^{19}$ Although this aspect to relationality will not be discussed in any depth in this article, an example of this can be found in the McDonald [72] case. In R (McDonald) $v$ Royal Borough of Kensington \& Chelsea [2011] UKSC 33, the applicant sought judicial review of the decision of her local authority to remove the provision of night time care to help her access the toilet. This service was replaced with incontinence pads. Ultimately the Supreme Court held, Lady Hale dissenting, that the removal of assistance to use the toilet was lawful, and did not violate the applicant's article 8 rights. On the analysis presented here, the provision of night time care would be indicative of enabling a maximally autonomous decision under the circumstances (the 
circumstances being that Elaine McDonald was not able to use the toilet without such assistance). Removal of the nighttime assistance reduced her ability to act in a maximally autonomous way. On the spectrum of autonomy presented in this paper, night time carers would represent maximal autonomy, incontinence pads would be on the spectrum somewhere below this. Of course this case also highlights how difficult courts would find it if they had to uphold only maximal autonomy, especially in light of increasing fiscal constraints on social care provision: [11].

${ }^{20} \mathrm{~A}$ continuous feature of empirical research in this area suggests that older people are continuously homogenized and misrepresented, or portrayed negatively in popular culture in many countries $[82,84]$.

${ }^{21}$ Recent proposals by the National Institute for Clinical Excellence (NICE) [24, 61], for example, suggest taking into consideration a treatment's 'wider societal benefit', such as the patient's capacity to return to work, as well as unpaid activities such as child-care, volunteering and domestic work. These proposals could potentially be ageism on two counts. Firstly, by placing these considerations at the centre of treatment decisions it places greater value on younger generations, who are more likely to be engaged in activities such as those listed above. Secondly, the term 'wider societal benefit' brings with it the assumptions that those who do not qualify are of little 'benefit' to society. Although not explicit, the ageism implicit in NICE's proposals are both etymological and substantive; they reflect and reinforce the more broader assumptions made about older people as disengaged or unproductive, and of little social value [16]

${ }^{22}$ This is not a purely hypothetical example. Evidence of such practices have been highlighted in particularly in the following reports: $[20,21,22,46]$.

${ }^{23}$ Similar facts were found in recent Nursing and Midwifery Council fitness to practice hearings: $[65,66]$.

${ }^{24}$ This example is derived in part from one presented by Clough and Brazier's in their recent article [16, p.3]. This is also a good example of the 'macro' and 'micro' level ageism distinction highlighted above; the doctor's ageist attitude may well have been informed by broader assumptions about older people, particularly older women, as 'asexual' $[19,80]$.

25 This argument has been made previously in relation to victims of domestic violence. See, for example, [76, pp.453-4]. 
${ }^{26}$ Of course, she may very well retain the potential to become a maximally autonomous agent if her cognitive functioning remains maximally operative: [4, p.658]. The argument presented here is not concerned with the way that oppression may hinder our cognitive development.

${ }^{27}$ Although this may very well be the case. For example, if an older person is discriminated against because of an age based rationing policy then this may still have an impact on that particular person's autonomy because of her age, but it is not akin to saying that her autonomy is curtailed because the way she views herself has changed.

${ }^{28}$ This is to take coercion in the legal sense such as in Re T (Adult: Refusal of Medical Treatment) [75] where there is direct coercion by one party over another's decision.

${ }^{29}$ These points are of particular contemporary relevance given the increasing debate over the legalization of assisted suicide, and more specifically, the fact that the universal prohibition on assisted suicide is designed to protect those who may seek help ending their lives simply due to lowered self-worth, for example: $R$ (Nicklinson \& Anor) v Ministry of Justice [2014] UKSC 38 [73, para. 311-315]

${ }^{30}$ Charpentier and Soulières' recent study indicates that the desire to not be seen as a troublemaker is very much present when deciding what course of action to take by older people in residential homes: 'I'm not doing anything to jeopardize my stay here. I like it here. So it's best to keep quiet.' (Mr. P., age 82 [translation]); 'If we complain too much we get a reputation as old troublemakers! Grumpy old complainers! It's easy to put negative labels on us. My philosophy is that if you want to be liked you have to be likeable. I do my best not to upset anyone.' (Ms. M., age 96 [translation]) [13, p.350]. A similar story (that of Betty) is presented by Les Bright: 'Unhappiness and depression gave way to fear, itself accompanied by a decision to do or say nothing that would inflame the situation further' [8, p.193].

${ }^{31}$ We could, of course, always argue that there is an acceptance in this example of the subjugated role, or that autonomy is compromised because Elizabeth doesn't want to upset her son, however neither of these threats are necessarily to do with the attitudes underpinning the actions in the first place.

${ }^{32}$ A study conducted in the Czech Republic by Buzgová and Ivanová [10] reported that only 11\% of care receivers noted some form of abuse, while even less (5\%) witnessed an act of mistreatment directed towards themselves or another older person in the institution, whilst on the other hand $27.8 \%$ of staff surveyed noted that they themselves had psychologically abused a 
patient, and $42.1 \%$ had observed another staff member psychologically and verbally abusing patients.

${ }^{33}$ Christman argues that ' $[\mathrm{t}] \mathrm{o}$ label such persons as non-autonomous because they do not stand in the proper social relations to their alleged "superiors" means that deliberations about the meaning of equality and legitimate authority is circumscribed to exclude voices who are otherwise...competent and authentic in ways that the procedural account of autonomy require' [14, at p. 157].

${ }^{34}$ Above, n.15.

35 Above, n.17.

36 'While traditional accounts of authenticity refer only to the isolated agent reflecting on his or her own desires, relational accounts "think of autonomy in terms of the forms of human interactions in which it will develop and flourish" (emphasis added), [14 at p. 148], quoting Nedelsky [62, at p. 16].

${ }^{37}$ See, for example, Naffine [60].

${ }^{38}$ This has been a predominant criticism of mandatory reporting systems to tackle elder abuse: $[30,48]$.

${ }^{39}$ It is questionable whether such a response can be effected by the law. This would, of course, depend on the type of interference suffered warranting legal intervention, which is why I am tentatively advancing this suggestion. Whether the law (in the form of the inherent jurisdiction or the MCA) should intervene in turn raises questions as to when the law ought to intervene. Clearly it would be impossible, and undesirable, to suggest that the court involves itself wherever it suspects ageism, particularly as ageism and its effects may well be very subtle and unidentifiable. In light of this, it is also important to explore alternative responses, such as the importance of human rights principles, the role of regulatory bodies, and the role professional education for health care workers can have in combatting ageism, which is generally outside the scope of this paper, but may provide fertile ground for further research.

40 [25] This case raised the legal issue of whether the inherent jurisdiction of the High Court remained to protect 'vulnerable adults' who do not fall within the remit of the Mental Capacity Act 2005. The case concerned an elderly couple who had been subjected to mistreatment by their son, $D L$, but nevertheless who retained capacity under the Mental Capacity Act. The Court 
of Appeal held unanimously that the inherent jurisdiction had survived notwithstanding the implementation of the Mental Capacity Act.

${ }^{41}$ [25, at para. 61], citing Lord Donaldson terminology in Re F (Mental Patient: Sterilisation) [1990] 2 AC 1

$42[25$, para. 64$]$

${ }^{43}$ In reality it is impossible to conceive of a decision that is made completely free from external pressures and therefore the most that can be hoped from any legal intervention is a removal of external pressures that may render the decision unauthentic.

${ }^{44}$ Such advocates can be appointed in certain circumstances to those who lack capacity under the Mental Capacity Act ss.35-41, however it may be that one response is to expand the role of such advocates to be included within the inherent jurisdiction. For a general overview of the benefits of a state appointed advocate system for people with disabilities, see [33].

${ }^{45}$ See, for example, $[49,68]$.

46 [1] The case concerned the application of Aintree University Hospitals NHS Foundation for a declaration that it would be in David James' best interests to have certain intrusive medical treatments withheld in the even of a deterioration in his clinical condition (he was, at the time of the application, in a state of low consciousness). Mr James' family, however, argued that while they understood that he could never regain full health, he still gained some pleasure from his current quality of life, in particular the visit from his family and friends. The Supreme Court found that when determining 'best interests', a subjective approach should be favoured. They also noted, however, that the Court of Appeal, despite erring in taking an objective stance, had, in fact, been correct to overturn the original decision given that $\mathrm{Mr}$ James' condition had deteriorated by the time the case reached the Court of Appeal, and it would no longer be in his best interests to provide invasive life-sustaining treatment by that point.

${ }^{47}$ By using Aintree as an analogous case here, I am not advocating the use of the Mental Capacity Act in such cases. There are, of course, those where the older person may well lack capacity under the Act's provisions, however the use of Aintree is simply to highlight that holistic and semi-relational approaches to an individual's welfare have begun to be recognized by even the highest appellate court in other contexts, and therefore there is no impediment, at least in theory, as to why this type of approach could not be taken elsewhere. 


\section{Refererences:}

1. Aintree University Hospitals NHS Foundation v James [2013] UKSC 67.

2. Anderson, J. \& Honneth, A. (2005). Autonomy, Vulnerability, Recognition and Justice. In J. Christman and J. Anderson (Eds.), Autonomy and the Challenge to Liberalism: New Essays. (pp.127-149). Cambridge: Cambridge University Press.

3. Becker, G. (1994). The Oldest Old: Autonomy in the Face of Frailty. Journal of Aging Studies, 8(1), 59-76.

4. Benson, P. (1994). Free Agency and Self-Worth. Journal of Philosophy, 91(12), 650-668.

5. Benson, P. (2000). Feeling Crazy: Self-Worth and the Social Character of Responsibility. In C. Mackenzie and N. Stoljar (Eds.), Relational Autonomy: Feminist Perspectives on Autonomy, Agency and the Social Self (pp. 72-93). Oxford: Oxford University Press.

6. Biggs, S. \& Haapala, I. (2013). Elder Mistreatment, Ageism and Human Rights. International Psychogeriatrics, 25(8), 1299-1306.

7. Black, K. \& Dobbs, D. (2014). Community-dwelling Older Adults' Perceptions of Dignity: Core Meanings, Challenges, Supports and Opportunities. Ageing and Society, 1-22. 
8. Bright, L. (1999). The Abuse of Older People in Institutional Settings: Residents' and Carers' Stories. In N. Stanley, J. Manthorpe and B. Penhale (Eds.), Institutional Abuse: Perspectives Across the Life Course, (pp. 191-204). London: Routledge.

9. Butler, R. (1975). Why Survive? Being Old in America. New York: Harper and Row.

10. Buzgová, R. \& Ivanová, K. (2011). Violation of Ethical Principles in Institutional Care for Older People. Nursing Ethics, 18, 64-78.

11. Carr, H. (2012). Rational Men and Difficult Women - R (on the Application of McDonald) v. Royal Borough of Kensington and Chelsea [2011] UKSC 33. Journal of Social Welfare and Family Law, 34(2), 219-230.

12. Charles, S. (2010). How Should Feminist Autonomy Theorists Respond to the Problem of Internalized Oppression? Social Theory and Practice, 36(3), 409-428.

13. Charpentier, M. \& Soulières, M. (2013). Elder Abuse and Neglect in Institutional Settings: The Resident's Perspective. Journal of Elder Abuse and Neglect, 25, 339-354.

14. Christman, J. (2004). Relational Autonomy, Liberal Individualism, and the Social Constitution of Selves. Philosophical Studies. 117, 143-164. 
15. Clough, B. (2014). What About Us? A Case for Legal Recognition of Interdependence in Informal Care Relationships. Journal of Social Welfare and Family Law, 36(2), 129-148.

16. Clough, B. \& Brazier, M. (2014). Never Too Old for Health and Human Rights. Medical Law International. 20 th August 2014. DOI: 10.1177/0968533214547557

17. Code, L. (1991). What Can She Know? Feminist Theory and the Construction of Knowledge. Ithaca: Cornell University Press.

18. Cracknell, R. (2010). The Ageing Population. House of Commons Library Research, London. Available at: http://www.parliament.uk/documents/commons/lib/research/key issues/Key -Issues-The-ageing-population2007.pdf (last accessed 11 August 2014).

19. Cuddy, A. J. et al. (2005). This Old Stereotype: The Pervasiveness and Persistence of the Elderly Stereotype. Journal of Social Issues, 61(2), 267-285.

20. Department of Health. (2009). Ageism and Age Discrimination in Primary and Community Care in the United Kingdom. Centre for Policy on Ageing, London.

21. Department of Health. (2009). Ageism and Age Discrimination in Social Care in the United Kingdom. Centre for Policy on Ageing, London.

22. Department of Health. (2009). Ageism and Age Discrimination in Secondary Health Care in the United Kingdom. Centre for Policy on Ageing, London. 
23. Department of Health, (2012). Long Term Conditions Compendium of Information: Third Edition. Department of Health, London.

24. Department of Health, (2014). Methodology for Estimating "Wider Societal Benefits" as the Net Production Impact of Treatments. Available at: http://www.nice.org.uk/Media/Default/About/what-we-do/NICE-

guidance/NICE-technology-appraisals/DH-Documentation-for-Wider-Societal-

Benefits.pdf (;ast accessed 28th October 2014).

25. DL v A Local Authority \& Others [2012] EWCA Civ 253.

26. Donnelly, M. (2010). Healthcare Decision-Making and the Law: Autonomy, Capacity and the Limits of Liberalism. Cambridge: Cambridge University Press.

27. Dunn, C. (2012). The Effect of Ageing on Autonomy. In H. Lesser (Ed.), Justice for Older People, (pp. 51-63). Amsterdam: Rodopi.

28. Dworkin, G. (1988). The Theory and Practice of Autonomy. Oxford: Oxford University Press.

29. Equality and Human Rights Commission. (2011). Close to home: An inquiry into older people and human rights in home care. EHRC, London. 
30. Faulkner, L. R. (1982). Mandating the Reporting of Suspected Cases of Elder Abuse: An Inappropriate, Ineffective and Ageist Response to the Abuse of Older Adults. Family Law Quarterly, 16, 69-91.

31. Fineman, M. A. (2004). The Autonomy Myth: A Theory of Dependency. London: The New Press.

32. Fineman, M. A. (2013). Equality, Autonomy and the Vulnerable Subject in Law and Politics. In M. A. Fineman and A. Grear (Eds.), Vulnerability: Reflections on a New Ethical Foundation for Law and Politics, (pp. 13-27). Farnham: Ashgate.

33. Flynn, E. (2013). Making Human Rights Meaningful for People with Disabilities: Advocacy, Access to Justice and Equality before the Law. The International Journal of Human Rights, 17(4), 491-510.

34. Foster, C. (2013). Autonomy in the Medico-Legal Courtroom: A Principle Fit For Purpose? Medical Law Review, 1-16.

35. Friedman, M. (2003). Autonomy, Gender, Politics. Oxford: Oxford University Press.

36. Garnett, M. (2014). The Autonomous Life: A Pure Social View. Australasian Journal of Philosophy, 92(1), 143-158.

37. Gilligan, C. (1993). In a Different Voice. Cambridge: Harvard University Press. 
38. Govier, T. (1993). Self-Trust, Autonomy and Self-Esteem. Hypatia, 8(1), 99120.

39. Greenberg, J. et al. (2004). Ageism: Denying the Face of the Future. In T. Nelson (Ed.), Ageism: Stereotyping and Prejudice Against Older Persons, (pp.2748). Cambridge: MIT Press.

40. Harding, R. (2012). Legal Constructions of Dementia: Discourses of Autonomy at the Margins of Capacity. Journal of Social Welfare and Family Law, $34(4), 425-442$.

41. Herring, J. (2009). Older People in Law and Society. Oxford: Oxford University Press.

42. Herring, J. (2013). Forging a relational approach: Best interests or human rights? Medical Law International, 13(1), 32-54.

43. Ho, A. (2008). Relational Autonomy or Undue Pressure? Family's Role in Medical Decision-Making. Scandinavian Journal of Caring Sciences, 22(1), 128135.

44. Hoagland, S. (1988). Lesbian Ethics: Toward New Value. Palo Alto, California: Institute of Lesbian Studies. 
45. Holroyd, J. (2009). Relational Autonomy and Paternalistic Interventions. Res Publica, 15(4), 321-336.

46. Joint Committee on Human Rights. (2007). The Human Rights of Older People in Healthcare: Eighteenth Report of Session 2006-07, Vol 1 - Report and Formal Minutes. The Stationery Office, London.

47. Keene, A. R. (23 January 2013). The Inherent Jurisdiction: Where Are We Now? Local Government Lawyer.

48. Kohn, N. A. (2009). Outliving Civil Rights. Washington University Law Review, 86(5), 1053-1115.

49. Kohn, N. A. et al. (2013). Supported Decision-Making: A Viable Alternative to Guardianship. Penn State Law Review, 117(4), 1111-1157.

50. LBL v RYJ and VJ [2010] EWHC 2665 (COP).

51. Lloyd, L. et al. (2014). Identity in the Fourth Age: Perseverance, Adaptation and Maintaining Dignity. Ageing and Society, 34(1), 1-19.

52. London Borough of Redbridge v G \& Others [2014] EWCOP 17.

53. London Borough of Redbridge v G \& Others [2014] EWCOP 485. 
54. Mackenzie, C. (2014a). Introduction: What is Vulnerability and Why Does it Matter for Moral Theory? In C. Mackenzie, W. Rogers and S. Dodds (Eds.), Vulnerability: New Essays in Ethics and Feminist Philosophy, (pp. 1-29). Oxford: Oxford University Press.

55. Mackenzie, C. (2014b). The Importance of Relational Autonomy and Capabilities for an Ethics of Vulnerability. In C. Mackenzie, W. Rogers and S. Dodds (Eds.), Vulnerability: New Essays in Ethics and Feminist Philosophy, (pp. 3359). Oxford: Oxford University Press.

56. Mackenzie, C. \& Rogers, W. (2013). Autonomy, Vulnerability and Capacity: A Philosophical Appraisal of the Mental Capacity Act. International Journal of Law in Context, 91(1), 37-52.

57. Mackenzie, C. \& Stoljar, N. (Eds). (2000a). Relational Autonomy: Feminist Perspectives on Autonomy, Agency and the Social Self. Oxford: Oxford University Press.

58. Mackenzie, C. \& Stoljar, N. (2000b). Autonomy Reconfigured. In C. Mackenzie and N. Stoljar (Eds.), Relational Autonomy: Feminist Perspectives on Autonomy, Agency and the Social Self (pp. 3-31). Oxford: Oxford University Press.

59. MacKinnon, C. A. (1983). Feminism, Marxism, Method, and the State: Towards Feminist Jurisprudence. Signs, 8(4), 635-658. 
60. Naffine, N. (1990). Law and the Sexes: Explorations in Feminists Jurisprudence. London: Allen \& Unwin.

61. National Institute for Health and Care Excellence. (2014). Consultation Paper: Value Based . Assassbilebte oft.Health Technolog http://www.nice.org.uk/Media/Default/About/what-we-do/NICEguidance/NICE-technology-appraisals/VBA-TA-Methods-Guide-forConsultation.pdf (last accessed 28th October 2014).

62. Nedelsky, J. (1989). Reconceiving Autonomy: Sources, Thoughts and Possibilities. Yale Journal of Law and Feminism, 1, 7-36.

63. Nedelsky, J. (2011). Law's Relations: A Relational Theory of Self, Autonomy and Law. Oxford: Oxford University Press.

64. Nelsen, P. (2010). Oppression, Autonomy and the Impossibility of the Inner Citadel. Studies in Philosophy and Education, 29(4), 333-349.

65. Nursing and Midwifery Council, Case 83A0008E, 27 March 2008.

66. Nursing and Midwifery Council, Case 09E0079C, 14 February 2013.

67. Oshana, M. (1998). Personal Autonomy and Society. Journal of Social Philosophy, 29(1), 81-102. 
68. Pathare, S. \& Shields, L. S. (2012). Supported Decision-Making for Persons with Mental Illness: A Review. Public Health Reviews, 34(2).

69. Pattinson, S. D. (2002). Undue Influence in the Context of Medical Treatment. Medical Law International, 5(4), 305-317.

70. Perkins, M. M. et al. (2012). Relational autonomy in assisted living: A focus on diverse care settings for older adults. Journal of Aging Studies, 26, 214-225.

71. Phelan, A. (2008). Elder Abuse, Ageism, Human Rights and Citizenship: Implications for Nursing Discourse. Nursing Inquiry, 15(4), 320-329.

72. R (McDonald) v Royal Borough of Kensington \& Chelsea [2011] UKSC 33.

73. R (Nicklinson \& Anor) v Ministry of Justice [2014] UKSC 38.

74. Re C [1994] 1 All ER 819.

75. Re T (Adult: Refusal of Medical Treatment) [1993] Fam 95.

76. Schwarz, A. W. (2007). Autonomy and Oppression: Beyond the Substantive and Content-Neutral Debate. Journal of Value Inquiry, 39, 443-457.

77. Sherwin S. \& Winsby, M. (2010). A relational perspective on autonomy for older adults residing in nursing homes. Health Expectations, 14, 182-190. 
78. Skirbekk, H. \& Nortvedt, P. (2014). Inadequate Treatment for Elderly Patients: Professional Norms and Tight Budgets Could Cause "Ageism" in Hospitals. Health Care Analysis, 22, 192-201.

79. Stoljar, N. (2000). Autonomy and the Feminist Intuition. In C. Mackenzie and N. Stoljar (Eds.), Relational Autonomy: Feminist Perspectives on Autonomy, Agency and the Social Self (pp. 94-111). Oxford: Oxford University Press.

80. Thornton, J. E. (2002). Myths of Ageing or Ageist Stereotypes. Educational Gerontology, 28, 301-312.

81. United Nations General Assembly Resolution A/RES/67/139. (20 December 2012). Towards a Comprehensive and Integral Legal Instrument to Promote and Protect the Rights and Dignity of Older Persons.

82. Vasil, L. \& Wass, H. (1993). Portrayal of the Elderly in the Media: A Literature Review and Implications for Educational Gerontologists. Educational Gerontology, 19(1), 71-85.

83. Verkerk, M. (1999). A Care Perspective on Coercion and Autonomy. Bioethics, 13(3/4), 358-368.

84. Wilińska, M. \& Cedersund, E. (2010) “Classic Ageism" or "Brutal Economy"? Old Age and Older People in the Polish Media. Journal of Aging Studies, 24(4), $335-343$. 